Marquette University

e-Publications@Marquette

Economics Faculty Research and Publications

Economics, Department of

$1-1-1988$

\title{
The Infant Mortality-Fertility Debate: Some International Evidence
}

Abdur Chowdhury

Marquette University, abdur.chowdhury@marquette.edu

Published version. Southern Economic Journal, Vol. 54, No. 3 (January 1988): 666-674. DOI. (C) 1988

Southern Economic Association. Used with permission.

Abdur R. Chowdhury was affiliated with Bentley College at the time of publication. 


\title{
The Infant Mortality-Fertility Debate: Some International Evidence*
}

\author{
ABDUR R. CHOWDHURY \\ Bentley College \\ Waltham, Massachusetts
}

\section{Introduction}

In recent years, an important debate has centered on the causal relationship between infant mortality and fertility. The different versions of the mortality-fertility proposition are based on the theory of demographic transition, choice theory, the modern economic theory of population and the Ricardian theory. Several studies have examined various aspects of the debate.' However, no consensus has emerged. For instance, the theory of the demographic transition as well as choice theory imply a lagged causality from infant mortality to fertility; while the Ricardian theory suggests that causality runs from fertility to mortality. Interdependence between these two variables, on the other hand, form the basis of the modern economic theory of population.

The lack of any clear-cut consensus may be due to the estimation problems inherent in these studies. First, many of these studies merely plot mortality and fertility through time and derive conclusions from a visual inspection of the plots. ${ }^{2}$ The finding of high correlation between these two variables do not, in any necessary sense, establish a causal relationship. The high correlation may be due to the common association of each variable with additional factors. Second, some of the studies are based on static cross-sectional evidence across different countries. ${ }^{3}$ One cannot properly infer from observations across countries at a point of time what will happen in one country over time. These studies are based on the dubious assumption of strong similarity of different nations. No attempt has been made to compare each individual country's time series. Moreover, the presence and direction of the causal relationship between infant mortality and fertility has also not been systematically analyzed. Third, there is ample evidence to assume that a lagged relationship may exist between infant mortality and fertility. ${ }^{4}$ The shape of the lag structure is crucial in determining the direction of causality between these two variables. The existing literature is lacking in a dynamic analysis essential to correctly analyze the mortality-fertility relationship. Despite the voluminous empirical research on the mortality-fertility relationship, the investigation has been mostly limited to static, cross-sectional analysis and visual inspection of the data. Substantially less work has been done involving a scientific and systematic treatment of the dynamic

*I would like to thank an anonymous referee for insightful comments and suggestions. The usual caveat applies.

1. See, for example, Cheung, Sharma and Shields [3], Heer [9], Scrimshaw [20] and Yamada [26] for an excellent exposition of the debate.

2. Exceptions include Cheung, Sharma and Shields [3] and Yamada [26].

3. See, for example, Chen [2] and Chowdhury et al. [4].

4. A rationale for the lagged relationship is provided in Cheung, Sharma and Shields [3]. 
lag structure involved. As yet there have been very little attempt to address this issue. This study intends to fill that gap in the literature.

The aim of this paper is to analyze empirically the causal relationship, if any, between infant mortality and fertility in thirty-five developing countries. The approach followed in this paper is significantly different from that of previous studies. The focus is upon the infant mortality rate, as measured by the number of deaths under one year per thousand live births in one calendar year, and its possible relationship with fertility rate, as measured by the number of live births per thousand female population between the ages of 10-49 years in one calendar year. The hypothesis that infant mortality causes fertility is tested. The possibility of a 'reverse causation' is also analyzed. A one-sided distributed lag test as proposed by Granger [7] is employed. However, instead of assuming the same lag-length for all variables, a statistical technique described in McMillin [16] is used to determine the appropriate lag length for each variable. Moreover, a more recent sample period is used.

Section II describes the different versions of the mortality-fertility proposition while section III explains the estimation technique. The empirical results are presented and analyzed in section IV. Section V contains a summary and conclusions.

\section{Mortality-Fertility Hypotheses ${ }^{5}$}

There are several versions of the mortality-fertility proposition. According to the theory of the demographic transition, infant mortality rate falls due to an increase in industrialization and urbanization, rises in literacy and living standards, and the application of improved medical practices. The decline in infant mortality leads to a subsequent decline in fertility. This theory suggests a lagged causal relationship between infant mortality and the fertility rate. The proponents of this theory argue that a pre-industrial society experiences high death rates associated with high birth rates. The necessity to preserve society encourages high birth rates. However, the process of economic development and industrialization by reducing mortality rates reduces the need for high fertility. The fertility rate eventually adjusts to the lower mortality rate after a certain lag.

In choice theory, infant mortality lowers the demand for surviving children by raising the costs for each survivor. According to Cheung, Sharma and Shields $[3,3]$ “. . . the demand for births and consequently fertility is a function of the optimal number of surviving children and the probability a child will survive infancy. The demand for surviving children, however, is thought to be negatively related to infant mortality while there is an expected positive relationship with the derived demand for births." Choice theory suggests two hypotheses in explaining how infant mortality influences fertility. The child replacement hypothesis states that parents react to a child's death by raising the number of subsequent births. However, this theory calls for incomplete replacement due to the costliness and physiological difficulties in rapidly increasing the pace of child bearing. Hence there is an inverse relationship between infant mortality and the number of surviving children. On the other hand, the child survival hypothesis states that a child's probability to survive influences the number of births. Empirical studies by Chowdhury et al. [4] for Pakistan and Bangladesh and May and Heer [15] for India provide support for the child survival hypothesis, while Olsen [17] finds support for the child replacement hypothesis in Columbia. Heer [9] has shown that parents' fertility behavior is influenced by their preference for the last child's sex and 
the number of surviving children of each sex. For instance, Heer and $\mathrm{Wu}$ [10] provide evidence that ". . . in Taiwan, births that follow previous child deaths are higher when the losses are male and the surviving children are female, because of the strong preference for sons" $[26,365]$.

Demographic transition theory differs from choice theory in as far as the lag structure and the sign of the coefficients are concerned. Transition theory implies potentially long but positive lags between infant mortality and fertility rates due to the intransigence of the pronatalist force; while choice theory suggests a relatively shorter lag with perhaps changing signs from negative to positive for families need some time to overcome the initial shock of an infant death [3].

The Ricardian theory is based on the proposition that economic development is neither necessary nor sufficient for fertility reduction. This theory implies that a rise in the actual wages above a subsistence level provides better health, greater life expectancy and improved economic conditions for families. This leads to a net reproduction rate above unity. The higher fertility rate is expected to cause an increase in mortality rates with some lag. This will occur mainly due to high risk births, e.g., births to very young and old mothers. This theory suggests that causality runs from fertility to mortality. Empirical evidence reported in Knodel and van de Walle [14], Knodel [13] and Wolfers and Scrimshaw [25] provides support for this view. ${ }^{6}$

Finally, the modern economic theory of population suggests that infant mortality and fertility are interdependent, i.e., a feedback exists between these two variables. Parents provide for food and healthcare for their child. Hence the outcome of the infant's health and their number depends upon the allocation of resources by the parents and is jointly determined by them. The major distinction between choice theory and modern economic theory of population is that in the former infant mortality is not a choice variable while in the latter both fertility and infant mortality are choice variables.

\section{Estimation Technique}

Identification of causal relationships among variables has been a major objective of economic research in recent years. Granger's [7] definition of causality between two variables in a time series context has stimulated great interest among researchers. Causality in the sense of Granger implies that $X$ causes $Y$ if the past values of $X$ can be used to predict $Y$ more accurately than simply using the past values of $Y$.

The technique commonly used for implementing the Granger test include the cross-correlation function method of Pierce and Haugh [18]; the one-sided distributed lag approach of Granger [7]; and the two-sided distributed lag approach of Sims [21]. Though the relative performance of various procedures stands far from settled, recent Monte Carlo studies by Guilkey and Salemi [8] and Geweke, Meese and Dent [6] have compared, among others, the performance of these procedures and concluded that Granger's method for testing causal ordering is superior to others. Therefore, Granger's method is employed in this study for investigating the causal relationship between infant mortality and fertility. ${ }^{7}$

6. van de Walle and Knodel [23] discusses the conditions in several European countries and suggests that (a) parts of France experienced fertility decline well before the spread of industrialization and urbanization and simultaneous with or prior to mortality declines, (b) in Hungary and Bulgaria, voluntary control of marital fertility occurred before any major shift toward industrialization occurred there. Similarly, Freedman [5] argues that certain regions in Asia (e.g., Sri Lanka and South India) have experienced significant fertility declines without simultaneous or prior modernization.

7. The Granger test is simple, straightforward and saves degrees of freedom. The limited number of observations 
Let $X$ and $Y$ be a pair of linear, covariance-stationary time series. Thus $X$ and $Y$ can be written as

$$
\begin{aligned}
X_{t} & =\sum_{i=1}^{m} a_{i} X_{t-i}+\sum_{j=1}^{n} b_{j} Y_{t-j}+e_{1 t} \\
Y_{t} & =\sum_{i=1}^{k} c_{i} Y_{t-i}+\sum_{j=1}^{p} d_{j} X_{t-j}+e_{2 t}
\end{aligned}
$$

where $e_{1}$ and $e_{2}$ are assumed to be $\operatorname{iid}\left(0, \sigma^{2}\right)$. To examine Granger-causality between $X$ and $Y$, the following hypotheses are tested: $b_{j}=0, j=1 \ldots n$ and $d_{j}=0, j=1 \ldots p$. If the former hypothesis is rejected but the latter is not, $Y$ causes $X$; whereas if the latter is rejected and the former is not, $X$ causes $Y$. If both are rejected, then there is a feedback between $X$ and $Y$. Failure to reject either of the two hypotheses implies independence between $X$ and $Y . F$-tests are used to test for the presence of Granger-causal relations. ${ }^{8}$

The Granger test typically employs the same lag length for all variables. This presents a potential problem. There is no a priori reason to believe that the same lag length is appropriate for all variables. In general, if the lag length of either $X$ or $Y$ (or both) is over-specified, the estimates will be unbiased but inefficient. Under-specified lag length of either $X$ or $Y$ (or both) will lead to biased estimates with a smaller variance. In order to avoid this problem, Akaike's final prediction error (FPE) criterion is used to specify the lag length of the right-hand side variable. ${ }^{9}$ After the appropriate lag lengths have been specified, $F$-test of the joint significance of the lagged values for each variable can be performed.

\section{Empirical Results}

There are three plausible hypotheses that will be tested in this paper. First, demographic transition and choice theory state that infant mortality causes the fertility rate. Second, Ricardian theory argues that the fertility rate causes infant mortality. Third, modern economic theory of population emphasizes an interdependency between infant mortality and fertility.

The Granger-causality tests are performed using annual time series for each of thirty-five countries. The countries are chosen on the basis of availability of data. ${ }^{10}$ They represent a wide geographic distribution and a considerable range of income per capita. The test presumes the use of stationary data and, typically, some transformation of the data is made in each country in order to attain stationarity. A regression of these transformed series on a constant and time yield insignificant coefficients while similar regressions of the untransformed series indicate the presence of trend.

available is an important consideration in using this test. The test is used with the usual misgivings. See for example, Zellner [27].

8. It has been argued that the bivariate Granger causality test may be biased due to omitted variables. See, for example, McMillin [16]. However, Yamada [26] has shown that it is very costly in terms of degrees of freedom to include more variables and/or more lags in the system when only a small number of observations are available to test the Granger causality.

9. To economize space, the estimation procedure is not discussed here. Interested readers are referred to McMillin [16].

10. The data on infant mortality and fertility are annual time series. They are taken from various issues of Demographic Yearbook, Statistical Yearbook and Population and Vital Statistics Report published by the Statistical Office of the United Nations. The sample period runs from 1947 to 1983. 
Table I: Granger-Causality Tests**

\begin{tabular}{|c|c|c|c|}
\hline \multirow[b]{2}{*}{ Country } & \multicolumn{2}{|c|}{$F$-statistics } & \multirow[b]{2}{*}{ Causality Results } \\
\hline & $I \rightarrow F$ & $F \rightarrow I$ & \\
\hline \multicolumn{4}{|l|}{ ASIA } \\
\hline \multicolumn{4}{|l|}{ Low-income countries } \\
\hline Bangladesh & $10.72 *(+)$ & 1.63 & $I \rightarrow F$ \\
\hline Burma & 1.88 & 0.72 & \\
\hline India & $7.90 *(+)$ & 1.08 & $I \rightarrow F$ \\
\hline Indonesia & $8.86 *(+)$ & 0.62 & $I \rightarrow F$ \\
\hline Nepal & 0.65 & 0.14 & \\
\hline Pakistan & $8.16^{*}(+)$ & 1.08 & $I \rightarrow F$ \\
\hline Sri Lanka & $7.68 *(+)$ & 1.13 & $I \rightarrow F$ \\
\hline \multicolumn{4}{|l|}{ Middle-income countries } \\
\hline Korea & $9.60 *(+)$ & 1.16 & $I \rightarrow F$ \\
\hline Malaysia & 0.98 & 1.02 & \\
\hline Philippines & 0.82 & 0.78 & \\
\hline Thailand & $10.16^{*}(+)$ & 0.16 & $I \rightarrow F$ \\
\hline \multicolumn{4}{|l|}{ SUB-SAHARAN AFRICA } \\
\hline \multicolumn{4}{|l|}{ Low-income countries } \\
\hline Ethiopia & 0.66 & $7.91 *(-)$ & $F \rightarrow I$ \\
\hline Ghana & $10.10 *(+)$ & $6.61 *(+)$ & $I \leftrightarrow F$ \\
\hline Kenya & 0.77 & 1.16 & \\
\hline Somalia & 0.42 & 1.10 & \\
\hline Sudan & 1.16 & $10.33 *(-)$ & $F \rightarrow I$ \\
\hline Tanzania & $8.66 *(+)$ & 0.67 & $I \rightarrow F$ \\
\hline Zaire & $9.62 *(+)$ & $8.16^{*}(+)$ & $I \leftrightarrow F$ \\
\hline \multicolumn{4}{|l|}{ Middle-income countries } \\
\hline Cameroon & $10.26 *(+)$ & $8.20 *(+)$ & $I \leftrightarrow F$ \\
\hline Ivory Coast & $6.63 *(+)$ & $9.16^{*}(+)$ & $I \leftrightarrow F$ \\
\hline Nigeria & $7.01 *(+)$ & $6.21 *(+)$ & $I \leftrightarrow F$ \\
\hline \multicolumn{4}{|l|}{ NORTH AFRICA AND MIDDLE EAST } \\
\hline \multicolumn{4}{|l|}{ Low-income countries } \\
\hline Egypt & $10.66 *(+)$ & 1.10 & $I \rightarrow F$ \\
\hline Tunisia & $8.70 *(+)$ & 0.98 & $I \rightarrow F$ \\
\hline \multicolumn{4}{|l|}{ Middle-income countries } \\
\hline Algeria & $10.68 *(+)$ & $8.87 *(+)$ & $I \leftrightarrow F$ \\
\hline Morocco & $9.66 *(+)$ & 1.32 & $I \rightarrow F$ \\
\hline Syria & 1.12 & 1.30 & \\
\hline \multicolumn{4}{|l|}{ LATIN AMERICA } \\
\hline \multicolumn{4}{|l|}{ Low-income countries } \\
\hline Haiti & $7.66 *(+)$ & $8.92 *(+)$ & $I \leftrightarrow F$ \\
\hline Bolivia & 0.66 & 1.71 & \\
\hline \multicolumn{4}{|l|}{ Middle-income countries } \\
\hline Brazil & $6.62 *(+)$ & $10.72 *(+)$ & $I \leftrightarrow F$ \\
\hline Chile & 0.68 & 1.12 & \\
\hline Colombia & $6.12 *(+)$ & 0.70 & $I \rightarrow F$ \\
\hline Dominican Republic & $8.66 *(+)$ & 0.80 & $I \rightarrow F$ \\
\hline Guatemala & 1.23 & 1.36 & \\
\hline Mexico & $8.77 *(+)$ & $7.30 *(+)$ & $I \leftrightarrow F$ \\
\hline Peru & $11.16^{*}(+)$ & 1.33 & $I \rightarrow F$ \\
\hline $\begin{array}{l}* * \\
\rightarrow \text { indicates unidirectional causality } \\
\leftrightarrow \text { indicates feedback }\end{array}$ & $\begin{array}{l}\text { sign in paren } \\
I=\text { Infant } \mathrm{m} \\
F=\text { Fertility } \\
* \text { significant }\end{array}$ & $\begin{array}{l}\text { shows the sign } \\
\text { rate } \\
\text { percent level }\end{array}$ & summed coefficients \\
\hline
\end{tabular}


The test results are presented in Table I." The value of the $F$-statistics reported in the first two columns are for the causality tests shown at the head of each column. Following the $F$-statistics, a sign in parentheses indicates the sign of the sum of the coefficients of the causal variable if it is significant at the 5 percent level. For example, for Bangladesh, the $F$-statistic of 10.72 indicates that the null hypothesis that infant mortality does not cause fertility can be rejected at the 5 percent level. The sum of the effects of infant mortality on the fertility rate is significantly positive at the 5 percent level. On the other hand, the $F$-statistic of 1.63 indicates that the null hypothesis that the fertility rate does not cause mortality cannot be rejected at the 5 percent level. The third column gives the test results for each country. The results show the direction of causality, if any, between infant mortality and fertility. If the null hypothesis that infant mortality does not cause fertility is rejected at the 5 percent level, the country is implied to support demographic transition and choice theory. On the other hand, rejection of the null hypothesis that fertility does not cause infant mortality indicates support for the Ricardian theory. Rejection of both the hypotheses implies support for the modern economic theory of population. In countries where neither of these tests can be rejected, no label is attached. ${ }^{12}$

Table I shows the lack of consistent results across different countries. The absence of any causal relationship between infant mortality and fertility is evident in ten countries. There is no statistically significant relationship between these two variables. This finding appears to reject the universality of the conventional wisdom regarding the causal link between infant mortality and fertility. In these countries (Bolivia, Burma, Chile, Guatemala, Kenya, Malaysia, Nepal, the Philippines, Somalia and Syria), it is possible that declines in mortality have largely been due to the advances of medicine, public health measures, or generally improved living conditions; while the fertility rate started to decline only as barriers of tradition and ignorance were broken down. While public health and its impact on mortality rest on public decision at the macro level, fertility decisions have remained in the private and individual micro level. However, causal relationship is present in the remaining twenty-five countries. Infant mortality causes fertility in fourteen countries. But in no case does lower infant mortality raise fertility. The sum of the infant mortality coefficient in the fertility equation is significantly positive. Moreover, the lag structure of the variables in each of these fourteen countries (Bangladesh, Columbia, Dominican Republic, Egypt, India, Indonesia, Korea, Morocco, Pakistan, Peru, Sri Lanka, Tanzania, Thailand and Tunisia) is relatively long and positive in sign. As pointed out in an earlier section and also discussed in Cheung, Sharma and Shields [3], both the transition and choice theory imply that a decline in infant mortality causes a decline in fertility. However, the two theories differ in as far as the lag structure and the sign of the coefficients are concerned. Transition theory implies potentially long but positive lags between infant mortality and fertility while choice theory suggests a relatively shorter lag with perhaps changing signs from negative to positive. Hence the results imply support for transition theory rather than choice theory. ${ }^{13}$

Evidence from nine countries provide support for the modern economic theory of popula-

11. Table I is based on a similar table reported in Jung and Marshall [12]. To conserve space, the coefficient estimates are not presented here, but are available from the author upon request. The Box-Pierce $Q$-statistics indicate the absence of serial correlation in the residuals.

12. This includes countries where the sum of the coefficients are statistically significant but no support is evident for the causal hypothesis. For a detailed discussion, see Jung and Marshall [12].

13. A detailed table showing the relevant lag structure is available from the author upon request. Results from these countries are contrary to the earlier findings for Bangladesh, Pakistan, India and Columbia as reported in Chen et al. [2], Chowdhury et al. [4], May and Heer [15] and Olsen [17] respectively. 
Table II: Causality Results by Regions*

\begin{tabular}{lcccrr}
\hline Region & $I \rightarrow F$ & $F \rightarrow I$ & $I \leftrightarrow F$ & $I \perp F$ & Total \\
\hline Asia & 7 & 0 & 0 & 4 & 11 \\
Sub-Saharan Africa & 1 & 2 & 5 & 2 & 10 \\
North Africa \& Middle East & 3 & 0 & 1 & 3 & 5 \\
Latin America & 3 & 0 & 9 & 1 & 9 \\
$\quad$ Total & 14 & 2 & & \\
$\quad *$ & & &
\end{tabular}

Table III: Causality Results by Income Distribution*

\begin{tabular}{lcccrr}
\hline Countries & $I \rightarrow F$ & $F \rightarrow I$ & $I \leftrightarrow F$ & $I \perp F$ & Total \\
\hline Low-income countries & 8 & 2 & 3 & 5 & 18 \\
Middle-income countries & 6 & 0 & 6 & 5 & 17 \\
$\quad$ Total & 14 & 2 & 9 & & \\
$\quad *$ & & & & \\
$\quad \rightarrow$ indicates unidirectional causality & & & &
\end{tabular}

tion which emphasizes an interdependency between the two variables. Neither of the two null hypotheses could be sustained at the 5 percent significance level in any of these nine countries. In each case, the sign of the summed coefficient is positive implying that reduced infant mortality lowers fertility which, in turn, further reduces infant mortality.

The results hardly show any support for the Ricardian theory. In only two countries (Ethiopia and Sudan), a unidirectional causality is evident from fertility to infant mortality. Further, the sum of the fertility coefficients in the infant mortality equation is significantly negative in Ethiopia and Sudan. This is contrary to the findings of strong positive correlation between these two variables as reported in Knodel [13], Knodel and van de Walle [14] and Wolfers and Scrimshaw [25]. Both Ethiopia and Sudan experienced a high population growth rate (about 2.5 percent) but a low infant mortality rate (less than 10 percent) during the sample period included in this study. It is possible that although the fertility rate has increased due to better economic conditions and consequently lower average age of marriage, the infant mortality rate has decreased due to its sensitivity to factors other than fertility, such as, industrialization and urbanization, availability of improved medical technology, a rise in living standards, etc.

A breakdown of the results in terms of geographical regions as well as income distribution is given in Table II and III respectively. Several interesting points can be noted from Table II. First, evidence from most of the countries sampled in Asia, North Africa and the Middle East supports demographic transition theory. Second, the modern economic theory of population finds support mostly in countries sampled in Sub-Saharan Africa and Latin America. Third, neither the Ricardian theory nor the modern economic theory of population find any support in Asia. Support for the Ricardian theory is also not evident in North Africa, the Middle East and Latin America. Finally, at least one-third of the countries sampled in Asia and Latin America show the absence 
of any causal link between infant mortality and fertility. Similar points can be noted in Table III. The modern economic theory finds support in twice as many middle-income countries as in lowincome countries. None of the middle-income countries support the Ricardian theory. Compared to the middle-income countries, a slightly higher percentage of the low-income countries support the transition theory.

\section{Conclusion}

The aim of this paper has been to analyze empirically the causal relationship, if any, between infant mortality and fertility in thirty-five developing countries. Although no consistent results are evident across different countries, more countries appear to support demographic transition theory as opposed to the other theories considered. The results hardly show any support for Ricardian theory. Moreover, many countries consistently show evidence of a long and positive lag structure as opposed to a short lag structure envisaged in choice theory. This is in sharp contrast to several empirical studies which found support for the child survival and child replacement hypothesis of choice theory in many developing countries. The difference in the results can be attributed to the lack of a dynamic and systematic analysis in these studies in correctly analyzing the mortality-fertility relationship. Finally, it should be noted that the researchers must be cautious in interpreting the results of this study. Questions may be raised regarding the use of registered birth and death rates as satisfactory evidence of fertility and mortality level in many developing countries; yet in the absence of any better alternative, these registered vital rates form the basis for many international cross-country comparison. The study provides at least some tentative results regarding the direction of causality between infant mortality and fertility.

\section{References}

1. Becker, Gary S. and H. Gregg Lewis, "On the Interaction between the Quantity and Quality of Children." Journal of Political Economy, March/April 1973, 279-88.

2. Chen, Lincoln C., Shamsa Ahmed, Melita Gesche, and W. Henry Mosley, "A Prospective Study of Birth Interval Dynamics in Rural Bangladesh.” Population Studies, July 1974, 277-97.

3. Cheung, Wai-Wah, Subhash Sharma and Michael P. Shields. "A Time Series Model of the Demographic Transition.” Discussion Paper Series No. 86-28, Southern Illinois University at Carbondale, November 1986.

4. Chowdhury, A. K. M. Alauddin, Atiqur R. Khan, and Lincoln C. Chen, "The Effect of Child Mortality Experience on Subsequent Fertility: in Pakistan and Bangladesh." Population Studies, July 1976, 249-61.

5. Freedman, Ronald, "Theories of Fertility Decline: A Reappraisal." Social Forces, 1979.

6. Geweke, John, Richard Meese and Warren Dent, "Comparing Alternative Tests of Causality in Temporal System: Analytic Results and Experimental Evidence.” Journal of Econometrics, February 1983, 161-94.

7. Granger, C. W. J., "Investigating Causal Relations by Econometric Models and Cross-Spectral Methods." Econometrica, July 1969, 424-38.

8. Guilkey, D. K. and M. K. Salemi, "Small Sample Properties of Three Tests for Granger-causal Ordering in a Bivariate Stochastic System." Review of Economics and Statistics, 1982, 660-80. $7-16$.

9. Heer, David M., "Infant and Child Mortality and the Demand for Children." Population Review, January 1983,

10. _ and Hsin-Ying Wu. "The Effect of Infant and Child Mortality and Preference for Sons Upon Fertility and Family Planning Behavior and Attitudes in Taiwan," in Population and Development in Southeast Asia, edited by John F. Kanter and Lee McMaffrey. Lexington, Massachusetts: Lexington Books, 1975, pp. 253-79.

11. Hsiao, Cheng, “Autoregressive Modelling and Money-Income Causality Detection.” Journal of Monetary Economics, January 1981, 85-106. 
12. Jung, Woo S. and Peyton J. Marshall, "Exports, Growth and Causality in Developing Countries." Journal of Development Economics, 18, 1985, 1-12.

13. Knodel, J., "Infant Mortality and Fertility in Three Bavarian Villages: An Analysis of Family Histories from the 19th Century." Population Studies, November 1968, 297-318.

14. _ and Etienne van de Walle, "Breast Feeding, Fertility and Infant Mortality: An Analysis of Some Early German Data.” Population Studies, September 1967, 109-31.

15. May, David A. and David M. Heer, "Son Survivorship Motivation and Family Size in India: A Computer Simulation." Population Studies, July 1968, 199-210.

16. McMillin, W. Douglas, "Federal Deficits, Macrostabilization Goals and Federal Reserve Behavior." Economic Inquiry, April 1986, 257-69.

17. Olsen, Randall J., "Estimating the Effect of Child Mortality on the Number of Births." Demography, November 1980, 429-43.

18. Pierce, David A. and Larry D. Haugh, "Causality in Temporal Systems: Characterizations and a Survey." Journal of Econometrics, May 1977, 265-93.

19. Pitchford, J. D. Population in Economic Growth. Amsterdam: North-Holland Publishing Company, 1974.

20. Scrimshaw, Susan, "Infant Mortality and Behavior in the Regulation of Family Size." Population and Development Review, September 1978, 383-403.

$\rightarrow$ Shields, Michael P. and Ronald L. Tracy, "Four Themes in Fertility Research." Southern Economic Journal, July 1986, 201-16.

22. Sims, Christopher A., "Money, Income and Causality." American Economic Review, September 1972, 540-42.

23. van de Walle, Etienne and J. Knodel, "Demographic Transition and Fertility Decline: The European Case." Proceedings of the Sydney Conference of the International Union for the Scientific Study of Population, 1968.

24. Willis, Robert J., "A New Approach to the Economic Theory of Fertility Behavior." Journal of Political Economy, March/April 1973, 14-64.

25. Wolfers, David and Susan Scrimshaw, "Child Survival and Intervals Between Pregnancies in Guayaquil, Ecuador." Population Studies, November 1975, 479-96.

$\rightarrow$ Yamada, Tadashi, "Causal Relationships between Infant Mortality and Fertility in Developed and Less Developed Countries.” Southern Economic Journal, October 1985, 364-70.

27. Zellner, Arnold, "Causality and Econometrics," Carnegie-Rochester Conference Series on Public Policy (supplement to Journal of Monetary Economics, 1979, 9-96. 